\title{
Formation of Communicative and Linguocultural Consciousness Based on the Film Text: Linguosynergetic Approach
}

\author{
Anna Belozerova ${ }^{1, *}$ \\ ${ }^{1}$ Don State Technical University, Gagarin sq., 1, 344003 Rostov-on-Don, Russia
}

\begin{abstract}
The article describes the experience of work at the Children's University of the Don State Technical University, where the author's program for the development of oral and written speech is being implemented. Fragments of lessons conducted using the technology of a pedagogical workshop are presented; a set of exercises that contribute to the formation of communicative and linguocultural consciousness when working with non-traditional means - a film text and a linguocultural diary. The linguosynergetic approach, chosen as the leading one, allows considering the model of linguistic comprehension of the language, taking into account the possibilities of the interconnected work of the human brain, nonlinearity in speech activity. It is concluded that the selected technology and teaching aids contribute to the activation of the speech-thinking activity of students.
\end{abstract}

\section{Introduction}

The challenges facing the linguodidactics in the 21 st century require continuous improvement of techniques and teaching methods based on the achievements of modern science. In this regard, one cannot but take into account the potential of cognitive linguistics, psycholinguistics, neurolinguistics, psychosemantics, cultural linguistics and other sciences that developed at the turn of the century. The focus of linguistic scientists is the cognitive study of language, which allows analyzing the connections between language and thinking, language and culture and consider language both as a tool for learning the world and as a mechanism for storing and transmitting knowledge about it. However, modern researchers are unanimous in the opinion that linguistics at this stage of its development needs a new paradigm, since aspects of the linguistic structure do not exist separately, but are related to each other and depend on the linguistic activity of a person and the cognitive structures of the person's brain. It seems reasonable to turn to linguosynergetics, which, without denying the systemic organization of the language, supplements it with provisions on openness, nonlinearity, changeability and self-organization (R.G. Piotrovsky, L.S. Pikhtovnikova). Being on the way of its formation, linguosynergetics as a science pays its attention to speech (speech activity) and language. There are studies in the field of the text synergetics by G.G. Moskalchuk, K.I. Belousov, I. Yu. Moiseeva, N.L. Myshkina and others; the discursive

*Corresponding author: belochka-04.80@mail.ru 
analysis in the logic of a synergetic approach is considered by N.F. Alefirenko, E.Yu. Muratova, S.K. Gural and others; the works of I.A. German, V.A. Pishchalnikova, L.V. Kushnina are devoted to the translation synergetics; V.I. Arshinov and Ya. I. Svirsky discuss synergetic movements in the language.

An analysis of the specialized literature allows concluding that at the present stage of the linguosynergetics development, the issues of synergetics of text and discourse are most actively considered; however, there are practically no works devoted to the methodology of teaching the Russian language based on the linguosynergetic approach (see e.g. the works of S.K. Gural, E.S. Antonova, L.P. Sychugova, A.V. Belozerova).

The objectives of the article are: 1) description of the developed models of classes within the framework of a pedagogical workshop using non-traditional teaching aids - a film text and a linguistic and cultural diary; 2) practical implementation of the formation of communicative and linguocultural consciousness within the linguosynergetic approach.

For this, a number of tasks should be solved: 1) description of the models of classes within the framework of the pedagogical workshop using the methods of linguosynergetics; 2) designation of a set of exercises for specific lessons, built on the principles of a pedagogical workshop using non-traditional teaching aids; 3) formulation of the ways to launch the speech-thinking activity of students in a lesson based on the technology of a pedagogical workshop, taking into account the linguosynergetic method.

The relevance of the research topic is based on the necessity of comprehending achievements of linguosynergetics and the use of its methods and techniques in teaching the Russian language.

\section{Materials and methods}

In this work, we will present the methods of forming the communicative and linguocultural consciousness of students of additional educational programs in the process of teaching language and speech to launch their speech-thinking activity, carried out by verbal and nonverbal means of domestic cinema. In our work we will adhere to the linguosynergetic approach, which, as L.P. Sychugova justly remarks, considers the processes of categorization, conceptualization and verbalization as a single synergistic process.

Let us designate the methodological principles underlying this work.

1. Reliance on the synergy of the brain and language. The theory of a synergetic model of thought-speech-language action was developed by V.K. Radzikhovskaya. In the process of using the language, one should take into account the figurative vision of the language nature, the possibilities of the interconnected work of the human brain, the nonlinearity in the organization of speech activity.

2. Language as a self-organizing communication system. The principle that was developed by T.A. Ladyzhenskaya continues to be actively implemented by the scientific school created by her.

3. The analysis of the text as a synergistic linguistic and speech unit is considered in the works by L.A. Khodyakova, N.A. Ippolitova, A.D. Deykina, O. N. Lyovushkina, S.I. Lvova, T.P. Malyavina, V.N. Meshcheryakov and others.

4. The formation of a conceptual picture of the world is developed by such practicing teachers as L.A. Khodyakova, L.P. Sychugova, M.S. Davydova, A.A. Sysolyatina, and N.L. Mishatina and I.P. Tsybulko see the source of the modern language formula in the linguoconceptocentric approach.

5. The principle of co-study of language and culture is synergistic too, since "the cultural and linguistic experience of the individual is involved in the text and, on the contrary, the text in the conceptual system of the individual" (I.A. Hermann). In our opinion, the works of T.K. 
Donskaya, L.A. Khodyakova, L.P. Sychugova, A.D. Deykina, S.I. Lvova and others are of interest.

6. The principle of communicativeness, which involves mastering the language as a means of communication through speech activity in order to meet the communicative needs of students.

7. The principle of anthropocentrism, which implies the all-round development of the personal potential of trainees, namely: cognitive abilities, emotional, spiritual, moral, creative development.

8. The principle of interactivity is methodically embodied in the works of Yu.G. Tsivyan, Yu.M. Lotman, Yu.N. Usov, S.N. Penzin, O.A. Baranova, G.S. Kolychev, A.V. Belozerova. The researchers believe that direct communication of students with the film text develops their ability to express personal opinions and attitudes during thoughtful viewing, listening, reading and reasoning.

Thus, we come to the conclusion that the linguosynergetic approach we have chosen helps to implement the principles of interconnected learning, allowing participants in the educational process to combine and use various types of human perception of the world through their organs, senses, and to subsequently consolidate the perceived data in consciousness verbally.

The focus of our attention is on communicative competence, which is formed by students when referring to works of art in speech development classes. We support the opinion of practical scientists that the introduction of adolescents to the memory of their ancestors by touching the beauty allows the subject of the educational process to perceive as a "bearer of individual and universal culture" [1]. We share the justly remark by L.A. Khodyakova that teaching language and speech in the context of culture "contributes to the formation of vital competencies - communicative and cultural studies, providing students' holistic view of the national picture of the world, knowledge of the world and themselves in it. There is the introduction to the culture of the native people, active and creative mastery of all types of activities, awareness of their significance and uniqueness as creative persons" [2].

At the Children's University, an educational project of the Don State Technical University, we are implementing an author's program for the development of speech "Reflection of the Russian soul in the linguistic picture of the world". The main goal of this program is the formation of communicative and linguocultural consciousness among students based on the synthesis of art. The idea is realized with the help of various types and genres of art: painting, architecture, music, theater, cinema, etc. At each lesson, there is a dialogue with art, during which students strive to convey their thoughts and feelings, experiences and emotions using verbal means. "Embodying verbally visual, auditory (pictorial, musical) images, schoolchildren learn to penetrate the secrets of the complex language of art, and a wide cultural context... expands the humanitarian space" [3], enriches the "cultural holding" [4]. Through the study of material containing cultural information, all components of the learning process are implemented: educational (assimilation of new things in order to expand the horizons), educational (the formation of spiritual and moral values), communicative (the ability to easily conduct a conversation about any cultural or historical event, draw up your judgment in writing using the vocabulary of a particular group of the cultural and historical layer).

The search for new methods and technologies for teaching the native language makes it possible to use non-traditional teaching aids e.g. film texts. Turning to cinematography allows not only acquainting adolescents with modern realities, but also turning to the previous historical stages of the society's life, broadening their horizons, because in addition to the linguistic range, the meaning of the film text is also formed with the help of musical, visual, choreographic and other messages. 
The use of cinema in the science of language is not new. The description of the "kinotext" definition was used in the works of Yu.G. Tsivyan, Yu.M. Lotman, Yu.N. Usov, S.N. Penzin, G.G. Slyshkin, O. Aronson and others. We share the point of view by G.G. Slyshkin and M.A. Efremova on that "the cinematic text is a coherent, integral and complete message, expressed with the help of verbal (linguistic) and non-verbal (iconic and/or index) signs, formed in accordance with the intention of a collective functionally differentiated author with the help of cinematic codes..." [quote on 5]. In our opinion, the key in this definition is the division of cinematic text signs into sound and visual ones. Linguistic signs (these include the speech of characters, voice-overs, songs, credits, inscriptions, etc.) make the film text related to the artistic text. They represent the basis for the formation of the language competence. The function of non-linguistic signs (noise, music, images and movements of characters, landscape, etc.) is to develop the communicative and linguocultural consciousness of students, because signs of this kind encourage participants in the educational process to generate statements of a creative nature: to give a portrait description of the movie characters, to describe their emotions when listening to background music, when looking at landscapes.

When choosing film texts for analysis, one should take into account a number of factors that affect the quality of assimilation of information and the formation of a linguistic picture of the world. These factors include:

1. The goal of training is the level that needs to be achieved with the help of various techniques, means and teaching methods. In our case, it is the formation of communicative and linguocultural consciousness.

2. Motivation level. In our opinion, one should choose Soviet or Russian film texts, the characters of which are of the same age or slightly older than the students, because their interests are clear to the younger generation. On the basis of viewing, individual-personal ideas are formed that have a beneficial effect on the imagination and, of course, are a source of powerful motivation in the study of the Russian language.

3. The level of the mental state and intellectual readiness of students (their age, working capacity, the formation of educational skills, activity and interest, the number and complexity of the educational material offered in the lesson).

4. The relationship between the participants in the educational process. We are convinced that: the success of the entire educational process depends on whether the co-creativity of the teacher and students takes place in the lesson. In the article, we present fragments of classes conducted using the technology of pedagogical workshops. The technology we have chosen proclaims the equality of all participants, the right of everyone to make mistakes and overcome them, and the refusal of evaluative activities. The teacher, realizing the democratic leadership style, acts as a mentor, guide, and expert. The atmosphere created by the teacher in class helps to overcome the psychological barrier, stimulates the creative self-development of the individual, and promotes the speech development.

5. The teacher's competence. This presupposes knowledge of the discipline being taught; the methodological "savvy" in the field of knowledge formation, skills and abilities; the ability to present material competently and enthusiastically. We share the opinion of L.P. Sychugova that a language teacher should understand "the individual characteristics of the vision of the surrounding reality by each of the students" [6]. A teacher who is convinced of the ability of students to think in new categories, new images, should have a high artistic and aesthetic education and impeccable aesthetic taste.

The linguistic component of the film text allows applying techniques of working with text to this component. For example, at the stage of preparation for the perception of the work as a whole (the so-called work with the text before reading, in our case - preparatory work with the film text before watching the film), we offer the following tasks: By the name of the feature motion picture, determine which genre this movie text belongs to, its semantic and 
emotional orientation. Carefully consider the film poster (film advertisement), guess what this movie is about, share your first impression of the characters, if they are depicted.

Working with text while reading can consist of several stages:

a) independent acquaintance with the text, checking the primary perception. Watch the movie trailer, determine its thematic focus. Was your idea of the movie the same before and after watching the trailer?

b) reading-listening, combined reading - sequential work with the text, when commenting on its content, explanation of new words, culture-specific elements.

c) text analysis - at this stage, the semantic parts of the text (= film fragments) are analyzed and an independent assessment of the characters' actions, understanding of their thoughts and feelings is performed. The student expresses own attitude to what was $\mathrm{read} / \mathrm{seen}$, formulates a complete statement in different genres (essay, sketch, reportage, review, etc.).

Working with the text after reading it involves discussion, correlating own opinion with the opinion of the author/director. At this stage, it is already possible to formulate the main idea of the work. Here, creative tasks based on emotions and imagination of students are appropriate.

The analysis of the non-linguistic part of the film text involves preparatory work that will help the participants in the educational process to master the terminology and correctly formulate their thoughts when drawing up a statement. Working with dictionaries of a cognitive type [7] contributes to the acquisition of this skill. For example, when talking about the landscape depicted in the film, or the angle chosen by the operator, it is advisable to refer to the dictionary records of "landscape" and "angle".

We believe that the use of the technology of pedagogical workshops within the framework of the linguosynergetic approach and the use of a linguistic-cultural diary and film text as a means of teaching contributes to the assimilation of chaotically perceived facts of the surrounding reality in the minds of students, i.e. specific, sensually visual images, systematization and ordering of the information received through mental actions, consolidation in the mind of knowledge about a conceivable conceptual image of the world on the basis of verbal and non-verbal signs [8]; in this work, an attempt is made to describe the methodology for the formation of communicative and linguocultural consciousness of adolescents using movie text in the context of the linguosynergetic methodology.

During the pedagogical workshop, students go from chaos through the bifurcation point to order, comprehending the laws of linguosynergetic thinking. At the induction stage (at the beginning of the pedagogical workshop), information about a particular event, realities and personalities is not structured in the consciousness of the lesson participant, there is no holistic understanding of the topic being studied; this corresponds to "chaos" within the framework of the linguosynergetic approach. At the culmination moment of the pedagogical workshop (at the break stage), faced with new knowledge, the students are at the point of choosing the answer/way of solving the problem, at the so-called "bifurcation point". It is essential to recall that the lesson format we have chosen does not imply assessment and gives each participant in the pedagogical workshop the right to make mistakes. At the final stage, students analyze the gained experience (spiritual, moral, cognitive); at the same stage, the teacher initiates reflection in the process of which in the minds of the workshop participants, the acquired knowledge is ordered through the student's mental actions and consolidation in the student's linguistic consciousness of “...the knowledge about a conceivable conceptual image of the world based on the use of linguistic or non-verbal signs" [1].

The work on filling out the linguocultural diary promotes the activation of all types of speech activity, making it possible to trace the formation of linguosynergetic thinking: from scattered ideas about the word-stimulus presented at the beginning of the lesson to a formalized statement in an independently chosen genre, observing grammatical norms and using the pictorial and expressive means of the Russian language. 
We will show fragments of work with texts of films dedicated to the Great Patriotic War - "We are from the future" [9] and "Zhenya, Zhenechka and "Katyusha" [10]. The choice of the films is not accidental: working with these tapes allows covering the widest range of problems of both educational and moral and ethical nature (acquaintance with the events of World War II, the victory of the Russian people over fascism, a person growing up in war, romantic relationships in military field conditions), as well as analyzing educational possibilities of cinematography.

Practical implementation of the speech development program (formation of communicative and linguocultural consciousness)

\subsection{Working with the text of the film "Zhenya, Zhenechka and "Katyusha".}

The analysis of the feature motion picture is carried out with the help of a linguistic and cultural diary [11], in the process of filling it out, students get acquainted with the story by B. Okudzhava "Be healthy, schoolboy", the time shown in the work; find the reasons that prompted the director V. Motyl to start writing the script; learn the history of the film creation, about the difficult fate of the film during its distribution, about the reaction of film critics and viewers. The obtained information is being "passed" through the consciousness of each student of the additional education program, and formalized reflections, notes, sketches about the read work, the seen film, emotions and impressions that overwhelmed during and after the lesson appear in the linguistic and cultural diary. The records help to keep the feelings and thoughts caused by the topic under study, return to the issues raised during the pedagogical workshop, analyze the stages of meeting with a book/film that did not leave the student indifferent. As an example, here are some tasks from a linguistic and cultural diary devoted to working with the film "Zhenya, Zhenechka and "Katyusha" [12]:

1. The pre-text work prepares for the perception of the text and consists of several parts: a) introduction to the lesson topic, cultural and historical commentary: 1. What associations does the word "war" evoke in you? 2. How do you think, should inexperienced young men and women fight? 3. Do you know works of art about the war, dedicated to those aspects of life that were not customary to describe? 4. Are you familiar with the works of B.Sh. Okudzhava, what works do you know? b) removal of lexical difficulties: Read the words and phrases that you come across in the text, determine their meaning, in case of difficulty, refer to the dictionary: katyusha, dugout, squadron, forward patrol, firing line, position, concentrate, pouch, crew, exemption from active duty...

2. The near-text work contributes to the mental activity of listeners and directs their attention to finding the required information: 1 . When reading the story, pay attention to how many plot lines the author shows. Why do you think he uses this technique? 2. Why does B. Okudzhava always make his hero be next to someone older, more experienced?

3 . The post-text work tests the understanding of the story content and the main idea of the text: 1 . Try to convey the meaning of the story in one complex sentence. 2. Describe the main character. 3 . Why do you think the story consists of small fragments? 4 . Why did the author use ring composition? 5. Why do you think this work was prohibited for a long time?

After working with the story "Be healthy, schoolboy", which served as the basis for the script of the film "Zhenya, Zhenechka and "Katyusha", it is recommended to do a little preparatory work before watching the film: 1. Imagine yourself as a director. What fragments of the story would you surely cinematize, and what would you not include in your film? Explain your choice. 2. Read the interview of M. Deputatov with the director of the film [13], highlight the information about B. Okudzhava and the story "Be healthy, schoolboy". Why do you think V. Motyl created the script for the future film based on this particular work? 3 . Listen to the song "Drops of the Danish King" (verses - B. Okudzhava, music - I. Schwartz). 
Suppose, what role will it play in the plot development. What are the "Drops of the Danish King", what do they heal?

The next step in the lesson is watching the film. In our opinion, the teacher is free to choose whether to watch the entire film or separate fragments thereof (this depends on the set goals and objectives, the preparedness and the age of the audience). After watching, we recommend to discuss what has been seen, tell about the first impression, about the questions that appeared as a result of watching or for which there were no answers. The teacher invites to discuss why the picture can be attributed to the genre of heroic-lyrical comedy, the narration - to the romantic story, and the main character can be compared with Don Quixote; the teacher asks to ponder the question: can the film make us understand our responsibility to history? During the exchange of views, we come to the conclusion that "Zhenya, Zhenechka and "Katyusha" is a film about the military everyday life of yesterday's schoolchildren who did not harden, did not become embittered, but matured men and retained honour and purity at the same time.

As a home assignment, it is proposed to write a creative work in one of the genres (review, essay, sketch, travel sketch, etc.): 1. Imagine that you are a war correspondent and were tasked to write about the heroic deed of Evgeny Kolyshkin, holder of the Order of Glory. What will your report be about? 2. Write a review of B. Okudzhava's story "Be healthy, schoolboy" or V. Motyl's film "Zhenya, Zhenechka and "Katyusha" (choosingly). 3. Write a travel essay "Heroic everyday life of young soldiers". 4. Make a sketch on the topic "It's not my absent-mindedness but my concentration that lets me down," etc.

In the process of linguoculturological analysis of the feature motion picture, students also perform lexicographic work that contributes to the enrichment of speech with lexical and grammatical means of their native language. Vocabulary entries, united by the semantic field of "Cinematography", are contacts that connect typical phenomenological and linguistic cognitive structures of knowledge in the field of cinema as one of the art forms, and help to develop the speech potential of students of additional education programs.

\subsection{Working with the text of the film "We are from the future"}

We will present a fragment of the lesson using the technology of creative workshops, dedicated to working with the text of the film "We are from the future" [14].

Workshop beginning. At this stage, an emotional pitch is created, students' interest in the problem of the lesson awakens: 1. Take a close look at the poster. Guess what the film is about? 2. Determine who the characters are. What can you say about each character? Why have you made such a conclusion? 3. Determine at what time the main events of the film will take place. Why have you decided that? How does this ad make you feel? 5. Try annotating the feature motion picture "We are from the future".

At the second stage, new knowledge is formed when students receive previously unknown information or expand their understanding of an already known event, object, phenomenon or person: 1. What associations do you have with the "war" word? What do you know about World War II? 2. Do you know the word "trailbreaker", who is he and what does he do? 3. Who are the "black" trailbreakers? Why do they interfere with the work of the search teams? 4. The original script for the film was called "Black trailbreakers". Why do you think the author of the film text changed the name? 5 . Watch the beginning of the film "We are from the future" (episode with the sale of orders and medals). What new have you learned about the main character? What makes him a successful digger?

Next, the semantic parts of the film text are analyzed (it is worth reminding that this article contains only a fragment of the lesson): 1 . Watch an episode of the film where the characters "work". What drives each of them? What are everyone's goals? 2. Watch the episode of "meeting the mother" carefully. How do young people treat the woman's words? How do 
they react to her request? 3. Guess what role this scene will play in the development of the film plot, justify your answer.

One of the stages of the creative workshop is to form own statement using didactic materials. During the lesson, we pay great attention to working with cognitive dictionaries. 1. Get acquainted with the Explanatory-Combinational Dictionary of Art [7], select entries that are useful for describing the work of a director, cameraman, artists, decorators. 2. Make a small statement on the topic: "The role of close-up picture in revealing the character", "Landscape as a characteristic of the character's inner world", "The choice of the required angle - the operator's success" (choosingly). 3. Choose one of the songs included in the film, make its linguistic and cultural analysis.

At the final stage, participants share the knowledge acquired during the workshop; they analyze own experience, feelings and thoughts, summarize as follows: 1. Was your idea of the film before watching the same as after? 2. What feelings did you have while watching the film? 3. How do you think, is it possible to say about the characters of the film that they have matured, changed? Justify your answer. 4. Read the end of the novel by Alexander Shevtsov (the scriptwriter) and conclude why the film was more optimistic.

The experience of working with the film text for the formation of language competence has shown that students react more emotionally and more actively to the tasks proposed by the teacher, more willingly express their point of view, entering into a discussion with classmates. In our opinion, the use of feature motion pictures in speech development lessons contributes not only to the formation of communicative and linguocultural consciousness, but also to the development of linguosynergetic thinking.

\section{Results}

The main results of the research carried out within the program for the development of speech "Reflection of the Russian soul in the linguistic picture of the world" are the developed models of classes in the framework of the pedagogical workshop using non-traditional teaching aids - the film text and the linguistic-cultural diary.

The purpose of the experiment is to determine the effectiveness of the means and methods we have chosen for the formation of communicative and linguocultural consciousness within the linguosynergetic approach. To do this, we analyzed the results of working with film texts ("We are from the future" and "Zhenya, Zhenechka and "Katyusha").

In the course of the experiment, a set of exercises of the linguistic and cultural diary on the lesson topic was tested (work with the text of the film "Zhenya, Zhenechka and "Katyusha") and an unconventional form of teaching - the technology of pedagogical workshops (work with the text of the film "We are from the future") was applied. A quantitative and qualitative analysis of the work of the participants in the speech development program showed a positive dynamics in the formation of skills and abilities acquired in the learning process at the beginning and at the end of the first year of mastering this program. Let us present the data in Table 1.

Table 1. Formed skills and abilities

\begin{tabular}{|c|c|c|}
\hline Formed skills and abilities & $\begin{array}{c}\text { At the beginning of } \\
\text { mastering the speech } \\
\text { development } \\
\text { program }\end{array}$ & $\begin{array}{c}\text { At the end of the } \\
\text { first year of } \\
\text { mastering the } \\
\text { speech development } \\
\text { program }\end{array}$ \\
\hline $\begin{array}{l}\text { 1. Ability to make decisions } \\
\text { independently without fear of } \\
\text { making mistakes }\end{array}$ & not formed & formed \\
\hline
\end{tabular}




\begin{tabular}{|l|c|c|}
\hline $\begin{array}{l}\text { 2. Ability to argue own position, } \\
\text { using knowledge gained during the } \\
\text { course of the program and personal } \\
\text { experience }\end{array}$ & not formed & formed \\
\hline $\begin{array}{l}\text { 3. Emotional and sensory attitude to } \\
\text { the lesson topic }\end{array}$ & partially formed & formed \\
\hline 4. Cultural holding of students & partially formed & formed \\
\hline $\begin{array}{l}\text { 5. Ability to correctly construct a } \\
\text { statement using grammatical and } \\
\text { lexical means of the Russian } \\
\text { language }\end{array}$ & partially formed & formed \\
\hline
\end{tabular}

The experience of working in the system of additional education has shown that the use of innovative technologies, methods and means of teaching increases the quality of training subjects of the educational process; the developed tasks and the confidential atmosphere created in the lesson contribute to the formation of communicative and linguocultural consciousness.

\section{Discussion}

In the method of teaching the native language, the relationship between language and culture is created through familiarizing students with the spiritual and moral values of the Russian people. Raising a competent spiritually developed personality is one of the leading goals of education. This is confirmed by the work of modern researchers. According to A.D. Deykina, the components of the historical and cultural content (especially the axiological one) are priority in the formulation of educational goals: "All the richness of the language $<\ldots>$, all the features of the norms and culture of speech motivate a positive attitude towards the studied subject, which entails the development of values by a person. The value series of ideas-judgments-beliefs is formed through tradition, and therefore through understanding the origins, consciousness of the history of the people and language" [15]. L.A. Khodyakova writes about the connection in the process of learning language and culture; according to her opinion, the development of linguocultural consciousness replenishes the vocabulary of students with a national-cultural linguistic component, art-history terms and creates an opportunity for fearless communication in a socio-cultural environment [16]. L.P. Sychugova believes that only the principles of co-study of language and art can ensure the development of communicative consciousness, when there is an integration of scientific knowledge, modern educational technologies and the appeal of "the consciousness and feelings of students to language learning based on the use of artistic values" [8].

The linguosynergetic approach in teaching language and speech, which we have chosen as the leading one, contributes to the implementation of a system of creative works and harmonization of the perception of works of art, and this is already an indicator of the formation of an emotional and sensory attitude to what is happening [17].

\section{Conclusions}

The implementation of the program "Reflection of the Russian soul in the linguistic picture of the world" in the context of the linguosynergetic approach contributes to the development of the cultural memory of students, the ability to competently use dictionaries, reference books, texts of fiction, film texts, as well as develops the need to constantly replenish their spiritual experience, expands the linguistic and cultural horizons, cultural holding. 
The author comes to the conclusion that the set of methodological exercises presented in the article and the described technology of pedagogical workshops allows students to compose monologic statements of various types and genres based on the film text as one of the sources of cultural information. Moreover, working with the text of works and their cinematizations expands the listeners' knowledge of the historical period presented, enriches their vocabulary, teaches them to express their thoughts correctly, to use the means of the Russian language, and introduces the spiritual heritage of the "Golden Fund" of the Soviet and Russian cinema. Thus, the formation of communicative and linguocultural consciousness takes place.

\section{References}

1. L. P. Sychugova, Science. Innovations: XVIII Russian Scientific Conference, Lingvosynergetic approach to the self-development of language and speech activity of future language specialists (on the example of work on the methodology of teaching the Russian language), 827 (2018)

2. L. A. Khodiakova, Speech development methods of the creative school children in the culture context: theory and practice, 188 (2018)

3. E.V. Lyubicheva, Russian Literature in a Foreign Audience, Learning Language as an Art, 75 (2015)

4. How to teach Russian language and literature to modern schoolchildren? School textbook today: Collective monograph, 61 (2018)

5. Media culture: glossary of terms and concepts (2021)

6. L.P. Sychugova, The modern methodological concept of the personal development of students in the process of learning the Russian language (for the anniversary of Professor A.D. Deykina): collective monograph, Linguoculturological approach: professional development of future language teachers, 263 (2014)

7. L. P. Sychugova, at al., Synergetic basis of author's educational, cognitive dictionaries. SHS Web of Conf., 69, 00017 CILDIAN-2019 Retrieved from: https://doi.org/10.1051/shsconf/20196900017 (2019)

8. L.P. Sychugova, Problems of the Russian language studies at the turn of the centuries, Word study and the part of the language and speech from linguocognitive and synergeric approaches, 334 (2017)

9. We're from the future (directed by Andrey Malyukov) URL: https://www.kinoteatr.ru/kino/movie/ros/9028/online/ (Last accessed 15.01.21)

10. 10 Zhenya, Zhenya and "Katyusha" (directed by Vladimir Motyl) URL: https://www.kino-teatr.ru/kino/movie/sov/2215/online/ (Last accessed 15.12.20)

11. A.V. Belozerova, Teacher for the future: language, culture, ersonatlity (to F. I. Buslaev's 200 th anniversary) : multi-authored monograph, Linguocultural diary as a realization model of methodological system of interrelated education, 104 (2018)

12. A.V. Belozerova, Dialogue of cultures. Theory and practice of teaching languages and literatures: VI International Scientific and Practical Conference, Formation of the national identity of students of the Children's University in the process of working with a feature motion picture, 104 (2018)

13. M. Deputatov, "Zhenya, Zhenechka and "Katyusha" was the first prohibition in the profession for the director Motyl", URL: http://www.closeup.ru/articles/detail.php?AID=8144 (Last accessed 11.12.2020)

14. A.V. Belozerova, Semantics. Functioning. Text. For the 70th anniversary of the birth of S.V. Chernova, Film text as a means of forming a linguistic picture of the world, 255 (2018) 
15. A.D. Deykina, Problems of modern education, Polyphony and harmony in teaching the Russian language, 1, 57 (2013)

16. L.A. Khodyakova, Methodology of mastering the analytical and synergetic skills in cultural context at the Russian language lessons and during extra: monograph, 214 (2020)

17. Sumina, N.V. at al. Linguosynergetic potential of the pedagogical workshop. E3S Web Conf., $210 \quad$ (2020) $18044 \quad$ Retrieved from:

https://doi.org/10.1051/e3sconf/202021018044 